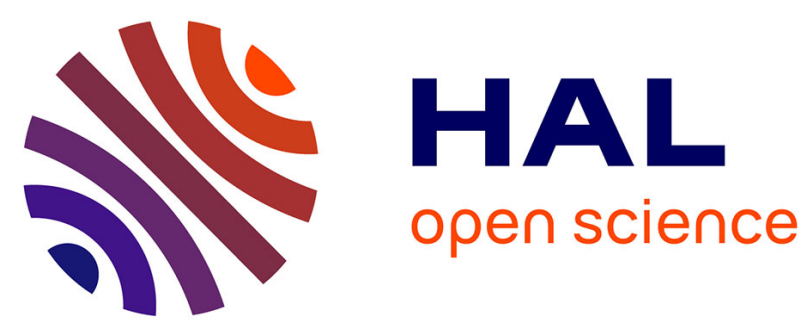

\title{
Calibration, field-testing, and error analysis of a gamma-ray probe for in situ measurement of dry bulk density
}

\author{
Patrick Bertuzzi, Laurent Bruckler, Y. Gabilly, J.C. Gaudu
}

\section{To cite this version:}

Patrick Bertuzzi, Laurent Bruckler, Y. Gabilly, J.C. Gaudu. Calibration, field-testing, and error analysis of a gamma-ray probe for in situ measurement of dry bulk density. Soil Science, 1987, 3, pp.425-436. hal-02719062

\section{HAL Id: hal-02719062 \\ https://hal.inrae.fr/hal-02719062}

Submitted on 1 Jun 2020

HAL is a multi-disciplinary open access archive for the deposit and dissemination of scientific research documents, whether they are published or not. The documents may come from teaching and research institutions in France or abroad, or from public or private research centers.
L'archive ouverte pluridisciplinaire HAL, est destinée au dépôt et à la diffusion de documents scientifiques de niveau recherche, publiés ou non, émanant des établissements d'enseignement et de recherche français ou étrangers, des laboratoires publics ou privés. 


\title{
CALIBRATION, FIELD-TESTING, AND ERROR ANALYSIS OF A GAMMA- RAY PROBE FOR IN SITU MEASUREMENT OF DRY BULK DENSITY
}

\author{
P. BERTUZZI, ${ }^{1}$ L. BRUCKLER, ${ }^{1}$ Y. GABILLY, ${ }^{2}$ AND J. C. GAUDU ${ }^{1}$
}

This paper describes a new gamma-ray probe for measuring dry bulk density in the field. This equipment can be used with three different tube spacings $(15,20$ and $30 \mathrm{~cm})$. Calibration procedures and local error analyses are proposed for two cases: (1) for the case where the access tubes are parallel, calibration equations are given for three tube spacings. The linear correlation coefficient obtained in the laboratory is satisfactory $(0.999)$, and a local error analysis shows that the standard deviation in the measured dry bulk density is small ( $\left.\pm 0.02 \mathrm{~g} / \mathrm{cm}^{3}\right)$; (2) when the access tubes are not parallel, a new calibration procedure is presented that accounts for and corrects measurement bias due to the deviating probe spacing. The standard deviation associated with the measured dry bulk density is greater $\left( \pm 0.05 \mathrm{~g} / \mathrm{cm}^{3}\right)$, but the measurements themselves are regarded as unbiased. After comparisons of core samplings and gamma-ray probe measurements, a field validation of the gamma-ray measurements is presented. Field validation was carried out on a variety of soils (clay, clay loam, loam, and silty clay loam), using gravimetric water contents that varied from $0.11-0.27$ and dry bulk densities ranging from 1.30-1.80 $\mathrm{g} \cdot \mathrm{cm}^{-\mathrm{s}}$. Finally, an example of dry bulk density field variability is shown, and the spatial variability is analyzed in regard to the measurement errors.

The gamma-ray transmission method is now classically used in field studies for measuring dry soil bulk density (Soane 1976). The field equipment described by different authors (Jensen and Mogensen 1966; Rawitz et al. 1982; Soane and Henshall 1979) consists of a radio-

${ }^{1}$ INRA, Station de Science du Sol, Domaine St Paul-BP 91, 84140 Montfavet, France.

${ }^{2}$ Centre d'Etude Technique de l'Equipement, Laboretoire Régional des Ponts et Chaussées, 23, Avenue de l'Amiral Chauvin-BP 66, 49130 Les Ponts de-Ce, France.

Received for publication 11 July 1986; revised 6 Feb. 1987. active source of ${ }^{187} \mathrm{Cs}$ and a detector, both located in stainless steel tubes inserted into the soil. The activity of the source is chosen according to the probe spacing, which is generally fixed to a constant value, and the detector is an $\mathrm{NaI}(\mathrm{Tl})$ crystal having a narrow diameter.

Practical field measurements face many problems:

1. The detected gamma ray is not monoenergetic under field conditions. The use of the general transmission law (Van Bavel et al. 1957) is not adequate to compute directly the dry bulk density, which makes it necessary to empirically calibrate the instrument. Some authors established universal laboratory calibration procedures (Jensen and Mogensen 1966; Soane and Henshall 1979), though others (Rawitz et al. 1982) proposed the use of direct field-calibration methods; the equipment in the latter case was found to be sensitive to some back-scattered radiation from outside the solid angle of view between the source and the detector. Thus, the measurements required large soil volumes around the access tube pairs, which nullified most of the alleged advantages of laboratory calibration.

2. Some authors (Soane 1968) discussed the importance of keeping a constant probe spacing when using the gamma-ray probe under field conditions. If the distance between the two stainless steel tubes differs from that used in the calibration procedure, then the dry bulk densities are obviously biased, leading to important and generally unacceptable errors.

3. An analysis of the measurement errors is useful to test the ability of the gamma-ray transmission probe to give satisfactory measurements in different types of practical applications.

This paper describes a new gamma-ray transmission probe having a variable probe spacing between $15-30 \mathrm{~cm}$. Two calibration procedures are presented, one of these taking into account the case where the parallelism between the access tubes is not exactly realized. Finally, a systematic analysis of the measurement errors is proposed; the analysis is subsequently used to study the field variability of the dry bulk density. 


\section{EQUIPMENT}

The equipment is developed at the Centre d'Etudes Techniques de l'Equipement (CETE), Laboratoire Régional des Ponts et Chaussées, Angers, France, in collaboration with the Institut National de la Recherche Agronomique (INRA), Soil Science Station, Montfavet, France, for field use. The main technical characteristics of the probe are presented in Table 1 and Fig. 1.

The equipment consists of two stainless steel tubes clamped together. One tube contains a radioactive source of ${ }^{187} \mathrm{Cs}$ enclosed in an aluminum capsule (0.8-mm wall thickness). The other tube holds an $\mathrm{NaI}(\mathrm{Tl})$ detector. The source and the detector are both uncollimated. The source tube is surrounded by an annulus container of tungsten carbide and lead for radiation safety. In operating conditions, the probe is locked against a stainless steel alignment jig that has a level mark for depth control and also ensures the stability of the probe. The alignment jig contains four holes. The probe clamp can slide along a guiding system upon the source tube to allow for three source-detector distances, depending on the requirement of the user.

The NaI(Tl) detector is optically bonded to a photomultiplier coupled with a pulse height discriminator located in the detector tube. They are linked by cable to a simple scaler/timer/supply unit. The discrimination level of photoenergy is fixed at $100 \mathrm{keV}$, combining mechanical (metallic cylinder with a $2-\mathrm{mm}$ lead and 1-mm cadmium wall thickness enclosing the detector) and electronic filtering (pulse height discriminator). Pulses of about 5-V amplitude are recorded on a portable scaler/timer/supply unit. The user can select four counting times. The power supply is given by four rechargeable batteries that can work continuously for $12 \mathrm{~h}$.

The vertical resolution obtained with the probe was studied in laboratory using different soil layers with contrasting dry bulk densities (Gabilly 1982). The main purpose of these experiments was to estimate the minimum depth increment that ensures the independence of two count measurements corresponding to the midplane of two adjacent soil layers. Whereas there is no general solution for this problem (Stengel et al. 1986), a 3- to 5-cm minimum depth increment ensures for practical purposes the independence of two adjacent measurements in field operating conditions.

\section{THEORY}

The gamma-ray attenuation law

Assuming a monoenergetic source, the general gamma-ray transmission law is given by

$$
C=C_{0} \cdot e^{-x\left(\rho_{s} \cdot \mu_{s}+\rho_{w} \cdot \mu_{w} \cdot \theta\right)}
$$

where

$$
\begin{aligned}
C= & \text { number of counts per unit time } \\
& \quad \text { (counts } \cdot \mathrm{s}^{-1} \text { ) } \\
C_{0}= & \text { incident number of counts per unit time } \\
& \quad\left(\text { counts } \cdot \mathrm{s}^{-1}\right) \\
x= & \text { soil attenuation length }(\mathrm{cm})
\end{aligned}
$$

\begin{tabular}{|c|c|c|}
\hline \multirow[t]{2}{*}{ Source } & Type & ${ }^{237} \mathrm{Cs}$ \\
\hline & Activity, $\mathrm{mCi}$ & 5 \\
\hline \multirow{2}{*}{ Detector } & Type & Nar(Tl) \\
\hline & $\overline{\text { Dimensions, } \mathrm{mm}}$ & 12.7 o.d., 25.0 , height \\
\hline \multirow[t]{2}{*}{ Photomultiplier } & Type & HAMAMATSU - R/647 \\
\hline & $\overline{\text { Dimensions, } \mathrm{mm}}$ & 12.0 o.d., 25.0 length \\
\hline Tube spacing & $\mathrm{mm}$ & $150-200-300$ \\
\hline Counting times & $\mathrm{s}$ & $10-30-100-300$ \\
\hline Measurement depths & $\mathrm{cm}$ & $2-50$ \\
\hline Weight & $\mathbf{k g}$ & 18 \\
\hline
\end{tabular}

TABLE 1

Technical characteristics of the gamma-ray probe 
Fig. 1. The gamma-ray probe.

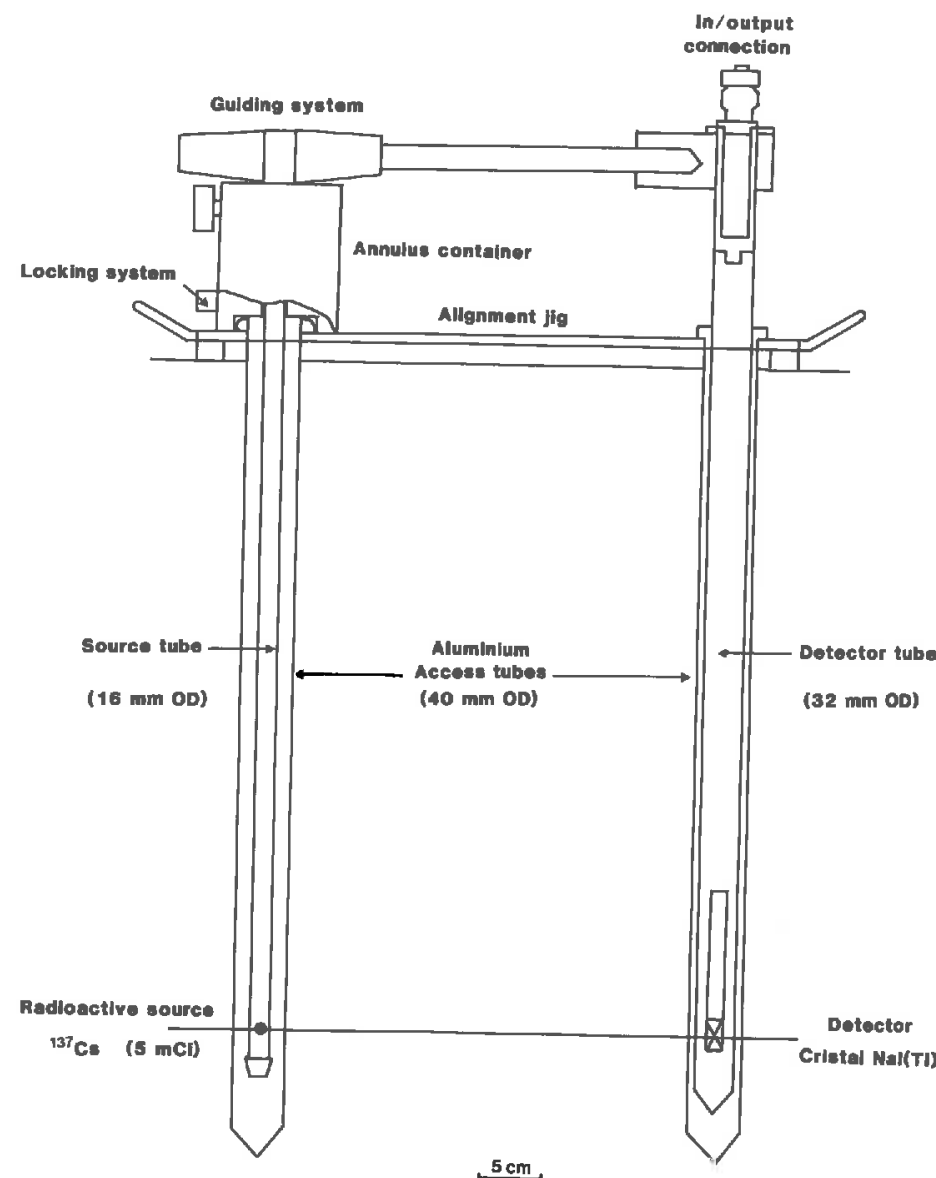

$\mu_{s}=$ soil mass attenuation coefficient $\left(\mathrm{cm}^{2}\right.$. $\mathrm{g}^{-1}$ )

$\mu_{w}=$ water mass attenuation coefficient $\left(\mathrm{cm}^{2} \cdot \mathrm{g}^{-1}\right)$

or

$\rho_{s}=$ dry soil bulk density of soil $\left(\mathrm{g} \cdot \mathrm{cm}^{-3}\right)$

$\rho_{u}=$ water specific mass $\left(\mathrm{g} \cdot \mathrm{cm}^{-3}\right)$

$\theta=$ volumetric water content $\left(\mathrm{cm}^{3} \cdot \mathrm{cm}^{-8}\right)$

Given that

$$
\theta=\frac{\rho_{s}}{\rho_{w}} \cdot W
$$

where $W$ is the gravimetric water content ( $g$. $\mathrm{g}^{-1}$ ) and combining Eqs. (1) and (2), we obtain

$$
C=C_{0} \cdot e^{-x_{p_{0}}\left(\mu_{4}+\mu_{w} \cdot W\right)}
$$

Introducing the mass attenuation coefficient of a reference material (here a calcareous soil having a mass attenuation coefficient $\left(\mu_{c}\right)$ ), Eq. (3) is rewritten as

$$
C=C_{0} \cdot e^{\left.-x \cdot \mu_{e} \cdot\left[\left(\mu_{s} / \mu_{e}\right)+\left(\mu_{w} / \mu_{c}\right) \cdot W\right) \cdot p_{0}\right]}
$$

where

$$
C=C_{0} e^{-x \mu_{c} \rho_{c}}
$$

$$
\rho_{c}=\left(\frac{\mu_{s}}{\mu_{c}}+\frac{\mu_{w}}{\mu_{c}} \cdot W\right) \cdot \rho_{s}
$$

Equations (5) and (6) show that any soil having a dry bulk density $\rho_{s}$, a gravimetric water content $W$, and a mass attenuation coefficient $\mu_{s}$ has exactly the same gamma-ray attenuation characteristics as a reference material having a mass attenuation coefficient $\left(\mu_{c}\right)$ and a referenced bulk density $\left(\rho_{c}\right)$ given by Eq. (6). Thus, calibration of the probe using different materials (i.e., of different chemical composition and with mass attenuation coefficients) is carried out with the calculated $\rho_{\mathrm{c}}$ values instead of the initially measured $\rho_{s}$ values for each material. In this way, all materials used in the calibration 
procedure are normalized relative to the calculated referenced bulk density $\left(\rho_{\mathrm{c}}\right)$.

\section{Theoretical calibration procedures}

Using a logarithmic transform, Eq. (5) can be rewritten

$$
\rho_{\mathrm{c}}=B_{1} \cdot \ln C+A_{1}
$$

where

$$
\begin{gathered}
B_{1}=-\frac{1}{x \cdot \mu_{c}} \\
A_{1}=\frac{1}{x \cdot \mu_{c}} \cdot \ln C_{0}
\end{gathered}
$$

Assuming monoenergetic gamma-ray transmission, the coefficients $\left(A_{1}, B_{1}\right)$ are regarded as physical constants. In reality, the detected gamma-ray transmission is not completely monoenergetic, and the coefficients $\left(A_{1}, B_{1}\right)$ must be seen as empirical statistical quantities of the calibration regression equation, Eq. (7). Furthermore, assuming that the "length-specific" calibration equation (as related to the corresponding specific transmission length or tube spacing) is known, then the use of Eq. (7) involves the same transmission length $(x)$ during calibration as well as field measurement. In practice it is sometimes difficult to insert the two access tubes vertically into the soil with a constant tube spacing at each depth of measurement. For this reason, it seems interesting to develop a more general procedure of calibration suitable for any transmission lengths $(x)$. Given that $e$ is the external radius of the access tube (cm), and $R_{0}$ is the distance between the source and the detector of the probe $(\mathrm{cm})$, then it follows that

$$
R_{0}=x+2 e
$$

To take into account the effect of different transmission lengths on the count $C_{0}$, we assume that the source is dimensionless with an isotropic gamma emission that views the detector under a solid angle $\Omega_{0}$. We introduce the hypothesis that the ratio of two counts $\left(C_{0}, C_{0}{ }^{\prime}\right)$ at two distances $\left(R_{0}, R_{0}{ }^{\prime}\right)$ is proportional to the two corresponding solid angles $\left(\Omega_{0}, \Omega_{0}{ }^{\prime}\right)$. Thus $C$ and $C_{0}$ are related by

$$
\frac{C_{0}}{C_{0}{ }^{\prime}}=K \frac{\Omega_{0}}{\Omega_{0}{ }^{\prime}}=K\left(\frac{R_{0}{ }^{\prime}}{R_{0}}\right)^{2}
$$

For another transmission length $\left(x^{\prime}\right)$, Eq. (5) can be written as

$$
C=C_{0} e^{-x^{\prime} \cdot \mu_{e} \cdot \rho_{e}}
$$

while also

$$
R_{0}^{\prime}=x^{\prime}+2 \cdot e
$$

Combining Eqs. (11) and (12) leads to

$$
C=K^{\prime} \cdot C_{0}\left(\frac{R_{0}}{R_{0}^{\prime}}\right)^{2} e^{-x^{\prime} \cdot \mu_{c} \cdot p_{c}}
$$

or

$$
C R_{0}{ }^{2}=K^{\prime} \cdot C_{0} \cdot R_{0}{ }^{2} \cdot e^{-x^{\prime} \cdot \mu_{c} \cdot p_{c}}
$$

Taking a natural logarithm of both sides, Eq. (15) can be written in the form

$$
x^{\prime} \rho_{c}=B_{2} \ln \left(C \cdot R_{0}{ }^{\prime 2}\right)+A_{2}
$$

where

$$
\begin{gathered}
B_{2}=-\frac{1}{\mu_{c}} \\
A_{2}=\frac{1}{\mu_{c}} \cdot \ln \left(K^{\prime} \cdot C_{0} \cdot R_{0}{ }^{2}\right)
\end{gathered}
$$

Note that the coefficients $\left(A_{2}, B_{2}\right)$ in Eq. (16) are independent of the transmission lengths $\left(x^{\prime}\right)$. For this reason, we will call the regression equation corresponding to Eq. (16) the average calibration line. Furthermore, the average calibration line takes into account the modified count $\left(C_{0}\right)$ according to the variation of the distance $\left(R_{0}\right)$ between the source and the detector of the probe. Finally, for any given $\left(x^{\prime}\right)$ value and corresponding $\left(R_{0}{ }^{\prime}\right)$ value, Eq. (16) is used for the estimation of the referenced bulk density $\left(\rho_{c}\right)$.

\section{Error analysis}

Rewriting Eq. (6), we obtain an algebraic expression for the dry bulk density $\left(\rho_{s}\right)$

$$
\begin{gathered}
\rho_{s}=\frac{\rho_{c}}{\frac{\mu_{s}}{\mu_{c}}+\frac{\mu_{w}}{\mu_{c}} \cdot W}=\frac{\rho_{c}}{r_{s}+r_{w} \cdot W} \\
r_{s}=\frac{\mu_{s}}{\mu_{c}} \text { and } r_{w}=\frac{\mu_{w}}{\mu_{c}}
\end{gathered}
$$

The total error in the measured dry bulk density consists of different components: (1) errors associated with the mass attenuation coefficients $\left(\mu_{s}, \mu_{c}, \mu_{w}\right)$ expressed in terms of ratio $\left(r_{s}, r_{w}\right) ;(2)$ an error in the measured gra- 
vimetric water content (W); and (3) an error resulting from the referenced bulk density estimation $\left(\rho_{c}\right)$ obtained with the calibration equations, Eqs. (7) or (16). Thus, the variance $s^{2}\left(\rho_{s}\right)$ is given by the sum of the contributions of the elementary variances, $s^{2}\left(r_{s}\right), s^{2}\left(r_{w}\right), s^{2}(W)$, and $s^{2}\left(\rho_{c}\right)$.

More generally, if, for any algebraic equation

$$
Z=f\left(z_{i}\right), \quad i=1, n
$$

we assume that the $z_{i}$ values are independent of each other, then the variance $s^{2}(Z)$ is given by

$$
s^{2}(Z)=\sum_{i=1}^{n}\left[\frac{\partial f}{\partial z_{i}}\right]^{2} \cdot s^{2}\left(z_{i}\right)
$$

Application of Eq. (22) leads to the expression for the error source components $\left(r_{s}, r_{w}, W, \rho_{c}\right)$ listed in Table $2 \mathrm{a}$. Table $2 \mathrm{~b}$ gives the expressions for $s^{2}\left(\rho_{c}\right)$ for the two calibration equations. In the case of the average calibration line, it appears that a supplementary error source $\left(s^{2}\left(x^{\prime}\right)\right)$ may arise due to the measurement of the transmission length $\left(x^{\prime}\right)$.

\section{MATERIALS AND METHODS}

\section{Laboratory calibration}

The probe was calibrated in the laboratory (Stengel et al. 1986) using blocks of different densities (Table 3). Dry bulk densities were first determined by geometrical measurements and weighing. They were controlled on a laboratory gamma-ray transmission equipment, and the agreement between the two methods was found to be excellent (Table 3). At the three tube spacings and using aluminum access tubes, more than 100000 counts are recorded in the midplane of each block at chosen counting times ( 30 s, $100 \mathrm{~s}, 300 \mathrm{~s})$. The data, using three replicates, were completed by measurements in water under similar conditions.

Parameters of the regression equations, Eqs. (7) and (16), were obtained by least-squares techniques.

Results for the "length-specific" calibration are shown in Fig. 2 and Table 4. For each tube spacing, the relationship between log count rate and referenced bulk density is linear with a

TABLE 2a

Algebraic equations of the error source components

\begin{tabular}{ll}
\hline Error source & $\frac{\text { Algebraic equations }}{\left(\frac{1}{r_{s}+r_{w} \cdot W}\right) \cdot \rho_{c}^{2} s^{2}\left(r_{s}\right)}$ \\
$\begin{array}{l}\text { Mass attenuation coefficient ratio }\left(r_{w}=\frac{\mu_{w}}{\mu_{c}}\right) \\
\text { Gravimetric water content }(W)\end{array}$ & $\begin{array}{l}\left(\frac{1}{r_{s}+r_{w} \cdot W}\right) \cdot W^{2} \cdot \rho_{c}^{2} s^{2}\left(r_{w}\right) \\
\text { Referenced bulk density }\left(\rho_{c}\right)\end{array}$ \\
\hline
\end{tabular}

TABLE 2b

Variances of predicted reference bulk density values according to the two types of calibration

\begin{tabular}{ll}
\hline \multicolumn{1}{c}{ Calibration model } & \multicolumn{1}{c}{ Variance of the predicted value } \\
\hline$Y=A_{0}+B_{0} X$ & $s^{2}(Y)=X^{2} \cdot s^{2}\left(B_{0}\right)+2 X \cdot s\left(A_{0}, B_{0}\right)+s^{2}\left(A_{0}\right)+s^{2}\left(e_{0}\right)$ \\
(general case) & $s^{2}(Y)$ variance of the predicted value $Y$ \\
& $s^{2}\left(B_{0}\right), s^{2}\left(A_{0}\right)$ variances of the regression parameters \\
& $s\left(A_{0}, B_{0}\right)$ covariance between the regression parameters \\
& $s^{2}\left(e_{0}\right)$ residual variance of the linear model \\
& $s^{2}\left(\rho_{c}\right)=[\ln (C)]^{2} \cdot s^{2}\left(B_{1}\right)+2 \cdot \ln (C) \cdot s\left(A_{1}, B_{1}\right)+s^{2}\left(A_{1}\right)+s^{2}\left(e_{1}\right)$ \\
$\rho_{c}=A_{1}+B_{1} \ln (C)$ & $s^{2}\left(\rho_{c} \cdot x^{\prime}\right)=\left[\ln \left(C \cdot R_{0}{ }^{2}\right)\right]^{2} \cdot s^{2}\left(B_{2}\right)+2 \ln \left(C \cdot R_{0}{ }^{2}\right) \cdot s\left(A_{2}, B_{2}\right)+s^{2}\left(A_{2}\right)+s^{2}\left(e_{2}\right)$ \\
$\rho_{c} \cdot x^{\prime}=A_{2}+B_{2} \ln \left(C \cdot R_{0}{ }^{\prime 2}\right)$ & $s^{2}\left(\rho_{c}\right)=\frac{1}{x^{\prime 2}}\left[s^{2}\left(\rho_{c} \cdot x^{\prime}\right)-\rho_{c}{ }^{2} \cdot s^{2}\left(x^{\prime}\right)\right]$ \\
$\left({ }^{\prime}\right.$ average" calibration) & \\
& $s^{2}\left(\rho_{c}\right)=\frac{1}{x^{\prime 2}}\left\{\left[\ln \left(C \cdot R_{0}{ }^{2}\right)\right]^{2} \cdot s^{2}\left(B_{2}\right)+2 \cdot \ln \left(C \cdot R_{0}{ }^{2}\right) \cdot s\left(A_{2}, B_{2}\right)+s^{2}\left(A_{2}\right)\right.$ \\
& $\left.+s^{2}\left(e_{2}\right)-\rho_{c}{ }^{2} \cdot s^{2}\left(x^{\prime}\right)\right\}$
\end{tabular}


TABLE 3

Characteristics of the laboratory calibration samples

\begin{tabular}{|c|c|c|c|c|c|}
\hline \multirow{2}{*}{ Name } & \multirow{2}{*}{$\begin{array}{c}\text { Chemical } \\
\text { Constitution }\end{array}$} & \multirow{2}{*}{$\begin{array}{c}\text { Dimensions, } \\
\text { cm }\end{array}$} & \multicolumn{2}{|c|}{ Bulk density, $\mathbf{g} \cdot \mathrm{cm}^{-\mathrm{a}}$} & \multirow{2}{*}{$\begin{array}{l}\text { Mass attenuation } \\
\text { coefficient, } \mathrm{cm}^{2} \\
\mathrm{~g}^{-1}(3)^{\circ}\end{array}$} \\
\hline & & & $(1)^{a}$ & $(2)^{a}$ & \\
\hline Technyl & $\begin{array}{l}\text { Synthetic plastic } \\
\text { material }\end{array}$ & $50 \times 40 \times 10$ & $1.144 \pm 0.005$ & $1.144 \pm 0.007$ & 0.0846 \\
\hline Terce & Calcareous rock & $50 \times 40 \times 10$ & $2.119 \pm 0.005$ & $2.121 \pm 0.013$ & 0.0776 \\
\hline Larrys & Calcareous rock & $50 \times 40 \times 15$ & $2.467 \pm 0.005$ & $2.484 \pm 0.018$ & 0.0776 \\
\hline Water & & $90 \times 40 \times 50$ & & & 0.0857 \\
\hline
\end{tabular}
$\mathrm{keV}$.

${ }^{a}(1)$, Geometrical measurement; (2), laboratory gamma-ray equipment; (3), theoretical coefficients at 662

FIG. 2. "Length-specific" calibration lines at three tube spacings.

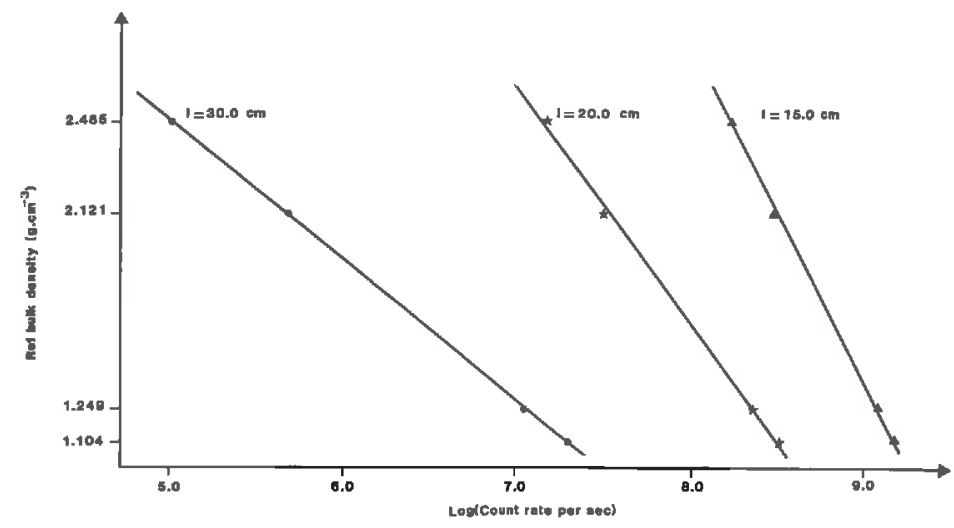

TABLE 4

Calculated parameters of the calibration equation

\begin{tabular}{|c|c|c|c|c|c|}
\hline \multirow{2}{*}{ Estimated coefficients } & & \multicolumn{3}{|c|}{ "Length-specific" calibration } & \multirow{2}{*}{ "Average" calibration } \\
\hline & & $x=15 \mathrm{~cm}$ & $x=20 \mathrm{~cm}$ & $x=30 \mathrm{~cm}$ & \\
\hline Slope & $B$ & -1.430 & -1.011 & -0.606 & -19.473 \\
\hline Intercept & $A$ & 14.234 & 9.701 & 5.540 & 311.590 \\
\hline Variance of $B$ & $s^{2}(B)$ & $0.534 \times 10^{-4}$ & $0.023 \times 10^{-4}$ & $1.830 \times 10^{-4}$ & 0.123 \\
\hline Variance of $A$ & $s^{2}(A)$ & $40.863 \times 10^{-4}$ & $1.487 \times 10^{-4}$ & $73.507 \times 10^{-4}$ & 24.423 \\
\hline Covariance between $A, B$ & $s(A, B)$ & $-4.666 \times 10^{-4}$ & $-0.187 \times 10^{-4}$ & $-11.466 \times 10^{-4}$ & -0.173 \\
\hline Residual variance & $s^{2}(e)$ & $0.353 \times 10^{-4}$ & $0.037 \times 10^{-4}$ & $6.688 \times 10^{-4}$ & 1.132 \\
\hline Number of couples & $n$ & 4 & 4 & 4 & 12 \\
\hline Linear correlation coefficient & $r$ & -0.999 & -0.999 & -0.998 & -0.998 \\
\hline
\end{tabular}

relatively high value of correlation coefficient. The slope of the linear regression varies with the tube spacing. The sensitivity was found to become better as the tube spacing increased.

Results for the "average" calibration are shown in Fig. 3 and Table 4. Twelve pairs of observation (three tube spacings $\times$ (three blocks + water)) were used in the least-squares analysis. The obtained relationship is linear, having a high correlation coefficient. The results are in good agreement with the general shape of the gamma transmission law, although the atten- uated gamma ray is not monoenergetic and not closed to a narrow beam on both sides of the photopeak.

\section{Field experiments}

Two aluminum tubes (40-mm o.d., 2-mm wall thickness) were installed in the soil using an alignment jig. At each depth increment (usually $3-5 \mathrm{~cm}$ ) a soil layer was augered through the access tubes. Soil samples were taken for the gravimetric water content measurements $(W)$ by oven-drying for $24 \mathrm{~h}$ at $105^{\circ} \mathrm{C}$. The tubes 
were subsequently pushed down, and the procedures were repeated until all tubes were inserted into the soil. The probe alignment jig was installed on top of the access tubes, and the probe locked on it. Count profiles were measured at the same depth locations as used for the gravimetric water content sampling, i.e., at the midpoint of the soil layers.

The distance between the access tubes was measured at two preselected depths, whereas the true distance between the source and the detector was calculated at each depth of measurement. These values are necessary to calculate the referenced bulk density $\left(\rho_{c}\right)$ using the "average" calibration equation.

\section{Field validation-comparison with the core sampling method}

Field tests were carried out on four contrasting soils (clay, clay loam, loam, and silty clay loam) and gravimetric water contents (0.11-0.27 $\mathrm{g} \cdot \mathrm{g}^{-1}$ ) in order to compare results obtained with the gamma-ray probe and those resulting from core-sampling measurements. At each site, the gamma-count profiles were measured from 3-48 $\mathrm{cm}$, at 3-cm depth increments. The tube spacing was fixed at $20 \mathrm{~cm}$, and a total counting time of $90 \mathrm{~s}$ (three replications of $30 \mathrm{~s}$ ) was selected. Next, a trench was dug, and two core samples were taken horizontally between the access tubes at two chosen depths having vertically homogeneous bulk densities and water contents. Core samples were obtained with a $150-\mathrm{mm}$ diameter, 72-mm-high stainless steel ring having a sharpened edge. The water content was again measured by oven-drying for $48 \mathrm{~h}$ at $105^{\circ} \mathrm{C}$.
Profiles of the probe dry bulk densities and associated errors were computed using the preliminary "average" calibration equation. An average of two values was compared to the corresponding core measurement using the procedure indicated in Fig. 4. Twenty-nine pairs of data were used, and a satisfactory linear relationship between them was obtained in the range of 1.30 $1.80 \mathrm{~g} \cdot \mathrm{cm}^{-3}$ dry bulk density and $0.11-0.27 \mathrm{gra}-$ vimetric water content (Fig. 5). The slope (0.967) of the experimental regression equation (dotted line) is smaller than 1 . This result suggests that dry bulk density data obtained with the probe are generally underestimated compared with the core-sampling method. However, the differences between the results of the two methods are relatively small for many or most field applications $\left( \pm 0.02- \pm 0.03 \mathrm{~g} \cdot \mathrm{cm}^{-3}\right)$. Thus,

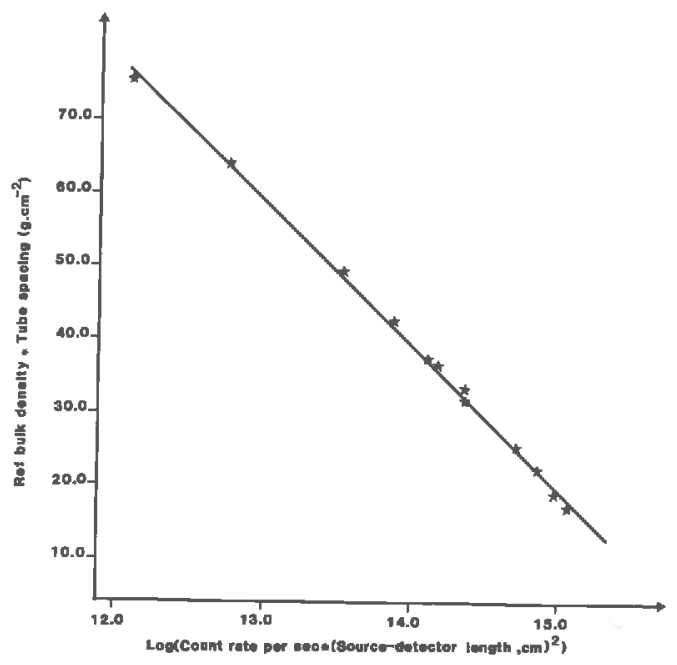

Fig. 3. "Average" calibration line.
FIG. 4. Relative position of the gamma-ray probe and core-sampling measurements.

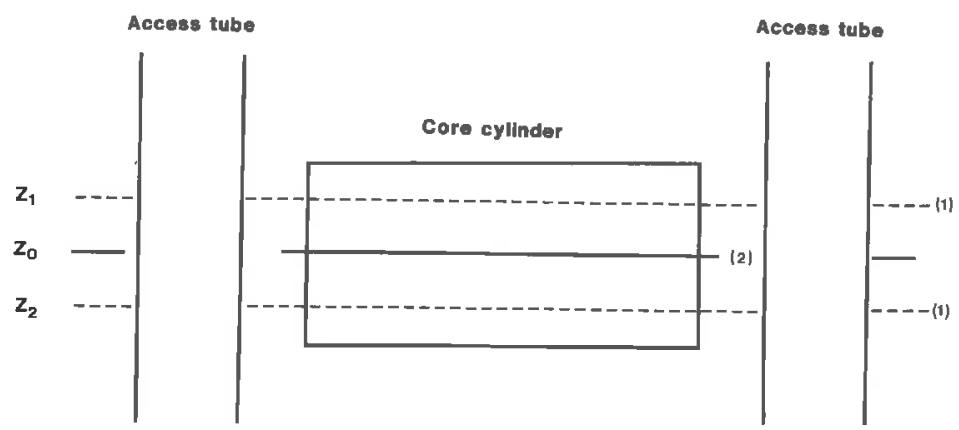

(1) Positlon of the gamma ray measurement

(2) Mid plane of the core measurement 
this experimental result gives a general evaluation of the ability of the probe to measure the dry bulk density under a large range of field conditions.

\section{RESULTS}

Bias due to the nonparallelism of the access tubes

Results of the "length-specific" calibration suggest a need to maintain a constant distance between the access tubes at each measurement depth. Field controls show that it is often difficult to keep the access tubes parallel. For example, tube spacing can vary $\pm 2 \mathrm{~cm}$ over a depth of $40 \mathrm{~cm}$. A simulation of varying distances (from 18-22 cm) between the access tubes was carried out to evaluate the bias on the dry bulk density measurement using the "length-specific" calibration equation at $20 \mathrm{~cm}$. At the selected distances and for three bulk densities and gravimetric water contents, we calculated the referenced bulk density $\left(\rho_{c}\right)$ and the corresponding count $(C)$ using the "average" calibration. The dry bulk density was then reestimated using the "length-specific" calibration equation at $20 \mathrm{~cm}$. Results are shown in Table 5. A great discrepancy is apparent between the chosen dry bulk density and those estimated with the "lengthspecific" calibration equation. A deviation of \pm $1 \mathrm{~cm}$ from the $20-\mathrm{cm}$ tube spacing gives a \pm 0.15 $\mathrm{g} \cdot \mathrm{cm}^{-3}$ systematic bias on the dry bulk density; the bias further increases as the deviation increases.

The use of the "average" calibration assumes that we are able to estimate the true distance between the access tubes. This was obtained under field conditions by digging a trench and precisely measuring the tube spacing at two chosen depths $( \pm 1 \mathrm{~mm})$ and then by calculating the true distance at any depth by using Thales' theorem.

\section{Error analysis}

Using the equations listed in Tables (2a) and (2b), we calculated the total variance of the error associated with the dry bulk density measurements, $s^{2}\left(\rho_{s}\right)$. The total variance consists of the elementary variance contributions of the four terms $\left(s^{2}\left(r_{s}\right), s^{2}\left(r_{w}\right), s^{2}(W)\right.$, and $\left.s^{2}\left(\rho_{c}\right)\right)$. The
Fig. 5. Comparison between the gamma-ray probe and the core-sampling measurements.

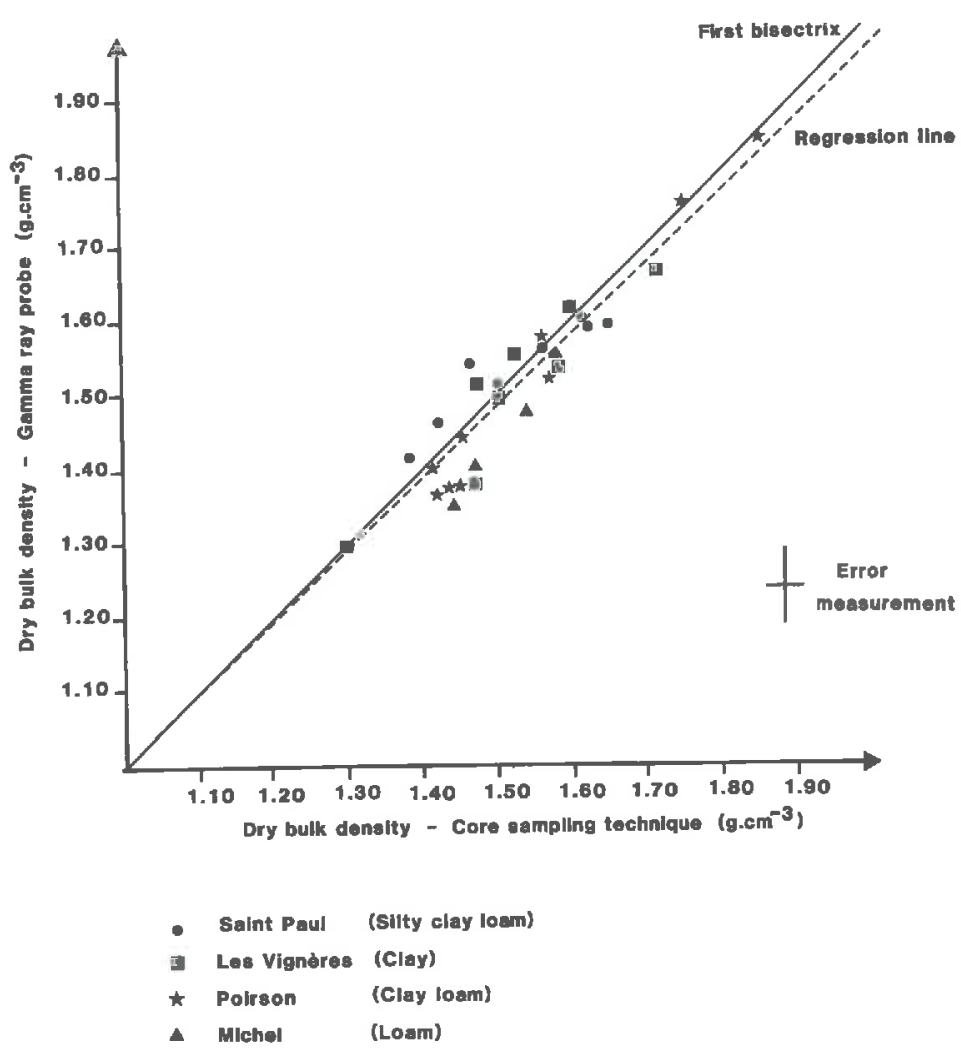


procedure assumes that the elementary terms are known. The values $s^{2}\left(r_{s}\right), s^{2}\left(r_{w}\right)$, and $s^{2}(W)$ were estimated from Table 6 , whereas the $s^{2}\left(\rho_{c}\right)$ values were directly derived from the statistical analysis of the chosen linear model (Table 2b). Error analyses were performed with the two calibration models, using a $20-\mathrm{cm}$ tube spacing, three different dry bulk densities, and two gravimetric water contents (Table 7).

Inspection of the results suggests the following.

1. The calculated standard deviation $s\left(\rho_{s}\right)$ is notably reduced by using "length-specific" calibration (compare $0.01 \mathrm{~g} \cdot \mathrm{cm}^{-3}$ to $0.05 \mathrm{~g} \cdot \mathrm{cm}^{-3}$

TABLE 5

Calculated bulk densities for differential tube spacings using a 20-cm "length-specific" calibration

\begin{tabular}{|c|c|c|c|c|c|c|c|c|c|}
\hline \multirow{3}{*}{$\begin{array}{c}\text { Gravimetric } \\
\text { water content, } \\
\mathrm{g} \cdot \mathrm{g}^{-1}\end{array}$} & \multicolumn{9}{|c|}{ Tube spacing, $\mathrm{cm}$} \\
\hline & 18.0 & 18.5 & 19.0 & 19.5 & 20.0 & 20.5 & 21.0 & 21.5 & 22.0 \\
\hline & \multicolumn{9}{|c|}{ Calculated dry bulk density, $\mathrm{g} \cdot \mathrm{cm}^{-3}$} \\
\hline 0.10 & 0.73 & 0.79 & 0.86 & 0.93 & 0.99 & 1.06 & 1.12 & 1.18 & 1.24 \\
\hline 0.20 & 0.75 & 0.81 & 0.87 & 0.94 & 1.00 & 1.06 & 1.12 & 1.18 & 1.23 \\
\hline 0.30 & 0.76 & 0.82 & 0.88 & 0.94 & 1.00 & 1.06 & 1.11 & 1.17 & 1.23 \\
\hline 0.10 & 1.01 & 1.08 & 1.16 & 1.23 & 1.30 & 1.38 & 1.45 & 1.52 & 1.59 \\
\hline 0.20 & 1.03 & 1.10 & 1.17 & 1.24 & 1.31 & 1.38 & 1.44 & 1.51 & 1.58 \\
\hline 0.30 & 1.04 & 1.11 & 1.18 & 1.25 & 1.31 & 1.38 & 1.44 & 1.51 & 1.57 \\
\hline 0.10 & 1.29 & 1.37 & 1.45 & 1.53 & 1.62 & 1.69 & 1.77 & 1.85 & 1.93 \\
\hline 0.20 & 1.31 & 1.39 & 1.46 & 1.54 & 1.62 & 1.70 & 1.77 & 1.85 & 1.92 \\
\hline 0.30 & 1.32 & 1.40 & 1.47 & 1.55 & 1.62 & 1.70 & 1.77 & 1.84 & 1.91 \\
\hline
\end{tabular}

TABLE 6

Estimated values of error source components

\begin{tabular}{lccccc}
\hline & Error source & Mean value & $\begin{array}{c}\text { Estimated } \\
\text { variance }\end{array}$ & Standard deviation & Relative error, \% \\
\hline Ratio & $r_{s}=\frac{\mu_{s}}{\mu_{c}}$ & 0.982 & $1 \times 10^{-4}$ & $1 \times 10^{-2}$ & 2.0 \\
& $r_{w}=\frac{\mu_{w}}{\mu_{c}}$ & 1.107 & $1 \times 10^{-4}$ & $1 \times 10^{-2}$ & 1.8 \\
Gravimetric & $W$ & 0.10 & $25 \times 10^{-6}$ & $5 \times 10^{-8}$ & 10.0 \\
$\begin{array}{c}\text { water con- } \\
\text { tent,g.g }\end{array}$ & & 0.20 & $25 \times 10^{-6}$ & $5 \times 10^{-3}$ & 5.0 \\
$\begin{array}{c}\text { Tube spacing, } \\
\text { cm }\end{array}$ & $x^{\prime a}$ & 20 & $25 \times 10^{-6}$ & $5 \times 10^{-3}$ & 3.3 \\
\hline
\end{tabular}

"Value used for the reference bulk density calculation with the "average" calibration.

TABLE 7

Estimated errors in the dry bulk density at $20 \mathrm{~cm}$ according to the two calibrations

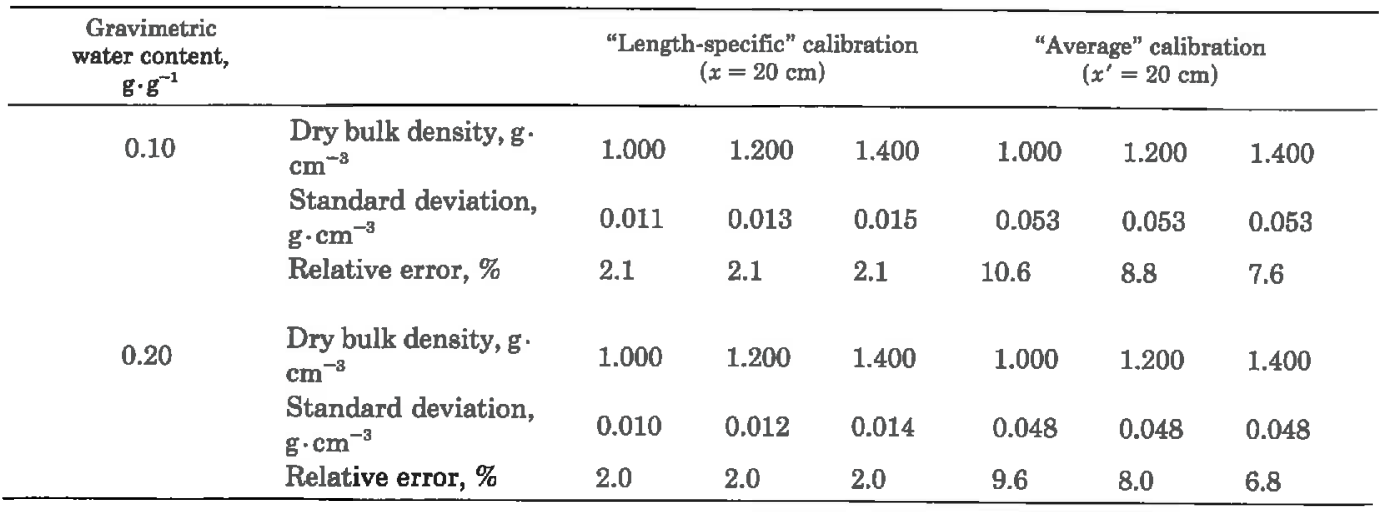


approximately); this is due to the term $s^{2}\left(\rho_{c}\right)$, which is greater for the "average" calibration.

2. Consequently, the relative contribution of the error sources to the total dry bulk density variance, $s^{2}\left(\rho_{s}\right)$ depends on the chosen calibration model (Table 8). For example, the contribution of the referenced bulk density is very small (close to $2-4 \%$ ) when using "length-specific" calibration, but becomes greater (more than $92 \%$ ) in the case of "average" calibration. Note that the contribution of the water mass attenuation ratio $\left(r_{w}\right)$ was found to be negligible in all cases. The contribution of gravimetric water content $(W)$ differed between the two calibration lines and could not be neglected when using "length-specific" calibration.

3 . These comparative results show that it is of practical interest to use "length-specific" calibration, which minimizes measurement errors when the two access tubes are positioned parallel. When this is not the case, loss of precision by using the "average" calibration becomes less than the risk of systematic bias due to the use of "length-specific" calibration.

\section{Spatial analysis}

Dry bulk density measurements using the gamma-ray probe were made under field conditions ( 0.4 ha, clay loam soil tilled with a rotary digging machine), to (1) evaluate the mean bulk density profile at the field level, (2) analyze the spatial distribution of the bulk density under these field conditions, and (3) compare the local error measurements to the spatial variability. Dry bulk density profiles were measured in 52 plots from 0-25 cm deep and in 5 of the 52 plots from 25-80 cm deep (Fig. 6). Structural layers appear clearly above and below the 30-cm depth. From 0-25 cm deep, the calculated standard deviation of the 52 values, at each depth, is less than $0.05 \mathrm{~g} \cdot \mathrm{cm}^{-3}$. From a practical point of view, it is possible to conclude that this field is spatially homogeneous. Furthermore, the dry bulk density frequencies can be considered to be sta-

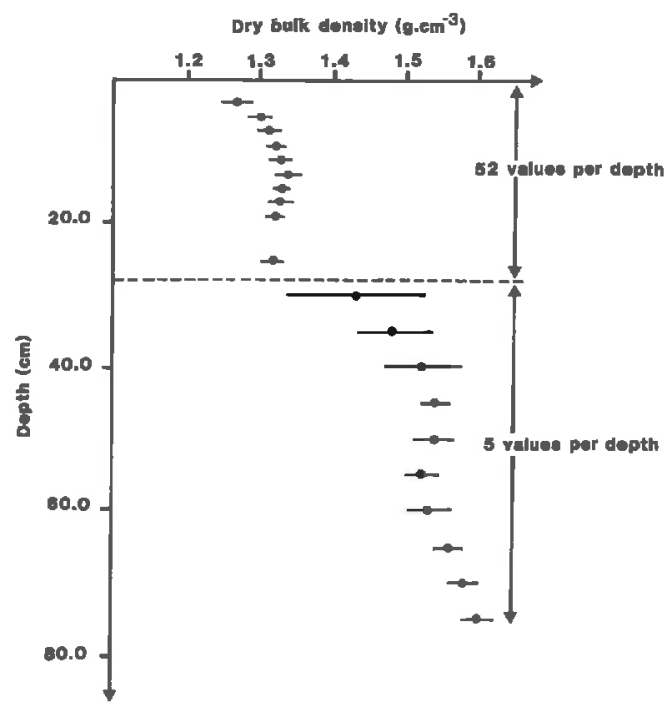

Fig. 6. Mean dry bulk density profile. The horizontal bars correspond to the confidence interval $(95 \%)$.

TABLE 8

Contribution of the error source components on the total variance of the estimated dry bulk density

\begin{tabular}{|c|c|c|c|c|c|c|c|}
\hline \multirow[t]{2}{*}{$\begin{array}{c}\begin{array}{c}\text { Gravimetric } \\
\text { water } \\
\text { content, } \mathrm{g} \cdot \\
\mathrm{g}^{-1}\end{array} \\
0.10\end{array}$} & & \multicolumn{3}{|c|}{ "Length-specific" calibration ( $x=20 \mathrm{~cm}$ ) } & \multicolumn{3}{|c|}{ "Average" calibration $\left(x^{\prime}=20 \mathrm{~cm}\right)$} \\
\hline & \multirow{4}{*}{$\begin{array}{l}\text { Dry bulk density, } \mathrm{g} \cdot \mathrm{cm}^{-3} \\
\text { Variance, } \mathrm{g}^{2} \mathrm{~cm}^{-6} \\
\text { Standard deviation, } \mathrm{g} \mathrm{cm}^{-3} \\
\text { Relative error, } \%\end{array}$} & 1.000 & 1.200 & 1.400 & 1.000 & 1.200 & 1.400 \\
\hline & & $1.15 \times 10^{-4}$ & $1.63 \times 10^{-4}$ & $2.20 \times 10^{-4}$ & $2.84 \times 10^{-8}$ & $2.81 \times 10^{-3}$ & $2.81 \times 10^{-3}$ \\
\hline & & 0.011 & 0.013 & 0.015 & 0.053 & 0.053 & 0.053 \\
\hline & & 2.1 & 2.1 & 2.1 & 10.6 & 8.8 & 7.6 \\
\hline & \multirow[t]{4}{*}{ Contribution, $\% r$} & 72.8 & 74.0 & 74.6 & 2.9 & 4.3 & 5.8 \\
\hline & & 0.7 & 0.7 & 0.7 & 0.1 & 0.1 & 0.1 \\
\hline & & 22.3 & 22.7 & 22.9 & 0.9 & 1.3 & 1,8 \\
\hline & & 4.1 & 2.6 & 1.8 & 96.1 & 94.3 & 91.3 \\
\hline \multirow{8}{*}{0.20} & Dry bulk density, $\mathrm{g} \mathrm{cm}^{-\mathrm{s}}$ & 1.000 & 1.200 & 1.400 & 1.000 & 1.200 & 1.400 \\
\hline & \multirow{2}{*}{$\begin{array}{l}\text { Variance, } \mathrm{g}^{2} \mathrm{~cm}^{-8} \\
\text { Standard deviation, } \mathrm{g} \mathrm{cm}^{-3}\end{array}$} & $0.97 \times 10^{-4}$ & $1.37 \times 10^{-4}$ & $1.85 \times 10^{-4}$ & $2.31 \times 10^{-3}$ & $2.29 \times 10^{-3}$ & $2.30 \times 10^{-3}$ \\
\hline & & 0.010 & 0.012 & 0.014 & 0.048 & 0.048 & 0.048 \\
\hline & Relative error, \% & 2.0 & 2.0 & 2.0 & 9.6 & 8.0 & 6.8 \\
\hline & \multirow[t]{4}{*}{ Contribution, \% $r$} & 71.4 & 72.4 & 73.0 & 3.0 & 4.3 & 5.9 \\
\hline & & 2.9 & 2.9 & 2.9 & 0.1 & 0.3 & 0.2 \\
\hline & & 21.9 & 22.2 & 22.4 & 0.9 & 1.3 & 1.8 \\
\hline & & 3.8 & 2.5 & 1.7 & 96.0 & 94.1 & 92.1 \\
\hline
\end{tabular}


tistically normal at each depth (see examples in Fig. 7); this experimental result is in good agreement with those obtained by other authors (Cassel and Bauer 1975). This preliminary analysis gives experimental results about the field variability of the dry bulk density, but its does not give any information about the field geostatistical characteristics. Figure 8 shows the experimental semivariogram for different depth measurements. It appears that in this case the experimental semivariogram does not show any trend, with probably a pure nugget effect. The values of $\gamma(0)$ are approximately between $20-30 \cdot 10^{-4}$ $\mathrm{g}^{2} \cdot \mathrm{cm}^{-6}$. In terms of the standard deviation, these values correspond to 0.045 and $0.055 \mathrm{~g}$. $\mathrm{cm}^{-3}$, respectively, which is the same order of magnitude as the measurement error. The observed nugget effect in this example appears to be due mainly to experimental equipment. This example shows the importance of having a preliminary, yet complete, measurement error analysis in order to interpret the observed trend of the experimental semivariogram.

\section{CONCLUSIONS}

The presented gamma-ray equipment for measuring field dry bulk densities has several advantages. First, a general procedure of calculations is given that solves the problem of systematic bias when the access tubes are not parallel. Second, a complete error analysis of the method shows that the calculated value of the standard deviation is acceptable either when the parallelism for access tube was obtained $(0.02$ $\mathrm{g} \cdot \mathrm{cm}^{-3}$, "length-specific" calibration) or when it is not (0.05 $\mathrm{g} \cdot \mathrm{cm}^{-3}$, "average" calibration). Third, the in situ gamma-ray and the core sampling methods gave approximately the same results for a large range of dry bulk densities. Finally, being nondestructive, the gamma-ray measurements made is possible to sample many

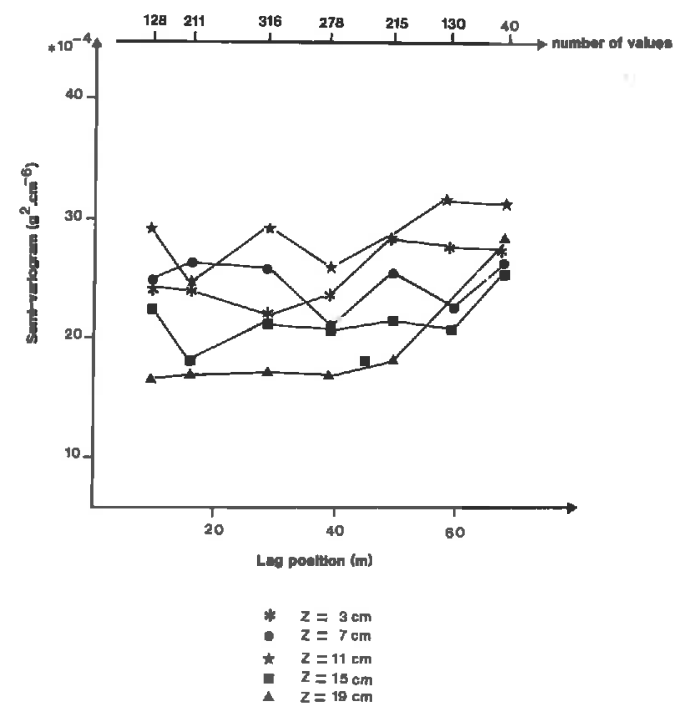

FIG. 8. Experimental semivariogram for the dry bulk density at five depths.
FIG. 7. Histogram of dry bulk density at two different depths (52 values).
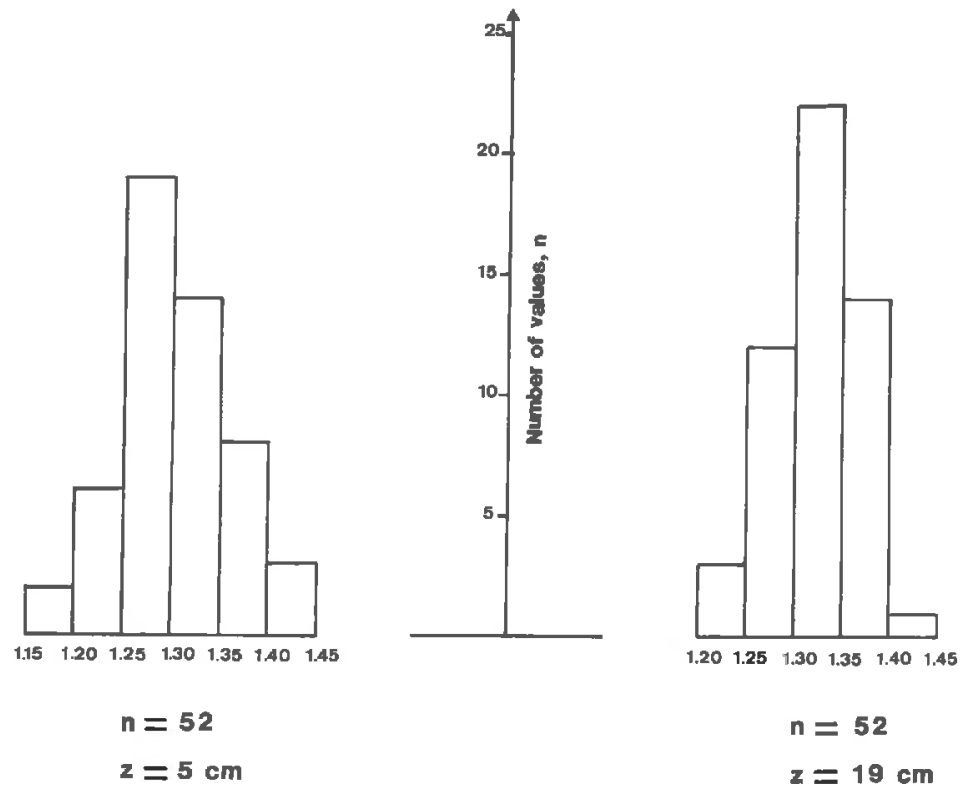
sites in a given spatially heterogeneous field. If done so, a spatial analysis of the dry bulk density and of the measurement errors are advisable, so that the measurement errors and the spatial variability in total variance can be correctly separated.

\section{REFERENCES}

Bruckler, L. 1983. Analyse théorique des erreurs de mesure de teneur en eau et de masse volumique par atténuation gamma. Bulletin du GFHN Juin, 13:7-33.

Cassel, D. K., and A. Bauer. 1975. Spatial variability in soils below depth of tillage: Bulk density and fifteen atmosphere percentage. Soil Sci. Soc. Am. Proc. 39:247-250.

Gabilly, Y. 1982. Etude des appareils à double sonde gammamétrique. Rapport interne, CETE, Laboratoire Régional des Ponts et Chaussées d'Angers.

Jense, Af. H. E., and V. O. Mogensen. 1966. Gammastraling for maling af endringer $i$ jordens vandindhold. Grundförbättring 4:333-343.
Rawitz, E., H. Etkin, and A. Hazan. 1982. Calibration and field testing of two probe gamma gauge. Soil Sci. Soc. Am. J. 46:461-465.

Soane, B. D. 1968. A gamma ray transmission method for the measurement of soil density in field tillage studies. J. Agric. Eng. Res. 13(4):340-349.

Soane, B. D. 1976. Gamma ray transmission systems for the in-situ measurement of soil packing stateReview paper. Scottish Institute of Agricultural Engineering Biennial Report 1974-1976, pp. 5986.

Soane, B. D., and J. K. Henshall. 1979. Spatial resolution and calibration characteristics of two narrow probe gamma ray transmission systems for the measurements of soil bulk density in-situ. J. Soil Sci. 30:517-528.

Stengel, P., Y. Gabilly, P. Bertuzzi, and J. C. Gaudu. 1986. La double sonde gamma LPC-INRA. Précision. Utilisation agronomique. Bull. Liaison Lab. Ponts et Chaussées, Janv-Fév., p. 141.

Van Bavel, C. H. M., N. Underwood, and S. R. Ragar. 1957. Transmission of gamma radiation by soils and soil densitometry. Soil Sci. Soc. Am. Proc 21:588-591. 